includes a comprehensive survey of the theory and that part of the section on experiments and phenomenological analysis covering $\beta$-decay, $\mu$-decay, $\mu$-capture and $\pi$ decay. The leptonic and non-leptonic decay of kaons and hyperons and parity-violating reactions will be included in next year's instalment. Other articles primarily of interest to those concerned with nuclear physics are those on photonuclear reactions, by Danos and Fuller; on the measurement of the masses of particles which undergo weak and electromagnetic decay and also of the mass of the antiproton, by Barkas; on non-spherical nuclei, by Rogers; on reactions between complex nuclei, by Greider; and on spin and parity determination of elementary particles, by Tripp.

Articles of more general interest are by Fleischer, Price and Walker, on particle track formation in solids and the use of solid-state detectors in nuclear science and geophysics; by Harbottle, on the chemical effects of nuclear transformations in inorganic solids; by Hart, on the radiation chemistry of aqueous solutions; by Blomeke and Roberts, on radioactive waste management, particularly that associated with reactor fuel processing; by Comar, on the movement of fallout radionuclides through the biosphere and man; and by Mole, on dose response relationships in mammalian radiobiology. J. E. TERRY

\section{Information and Communication Theory}

By A. M. Rosie. (Electronic User Series.) Pp. xii + 175. (London and Glasgow: Blackie and Son, Ltd., 1966.) 32s. 6d. net.

THIs volume is one in a series ostensibly written for "qualified scientists and engineers for whom electronics is a fringe activity". The text is based on lectures given in final-year and postgraduate courses in a school of electrical engineering and is, therefore, potentially useful to those for whom electronics is much more than a "fringe activity". The author has tried to restrict the range of mathematical ideas used in presenting the theory and in two chapters has given brief introductions to such topics as the Fourier transform and probability theory. Nevertheless, the book is suitable for only two types of readerthose for whom these introductory chapters can serve as revision and those able to absorb new mathematical ideas quickly.

About two-thirds of the book is concerned with developing the ideas of information theory and applying them in the study of communication systems. The material is presented clearly and the examples and illustrations are well chosen. The chapters on "Sources and Channels" and "Ideal Communication Systems" are particularly good and these and two following sections-concerned with engineering applications of the theory-will be useful to undergraduates reading for degrees in electrical engineering.

The final chapter is concerned with the uses of information theory in biology, neurophysiology and psychology and with pattern recognition. This chapter is not up to the standard of the remainder of the text and the problems it attempts to treat cannot be dealt with in the space available.

J. T. Allanson

\section{The Plastic Methods of Structural Analysis}

By B. G. Neal. Second edition. Pp. xiii + 358. (London: Science Paperbacks and Chapman and Hall, Ltd., 1965.) $25 s$.

THE Steel Structures Research Committee published its final report on elastic design in 1936, and this date may be taken conveniently as that of the start of three decades of work on plastic theory. In the first decade Sir John Baker investigated simple beams and frames (and applied the findings to the design of the Morrison shelter); this phase closed in 1948, when a clause permitting plastic design of steel structures was inserted in British Standard 449. The second decade saw the formalization of the theoretical basis of the method; the theorems of the mathematical theory of plasticity were applied to the problem of the building frame, and immediate advances were made. For example, the powerful technique of combination of mechanisms was developed, with which Prof. Neal's name is associated. This period closed in 1956 with the publication by Baker et al. of The Steel Skeleton II; in the same year Neal's book was published (second edition 1963, now reprinted as a paperback). Since 1956 detailed problems of the design of structural elements have been investigated, but the main advance during the past ten years lies perhaps in the slow assimilation of plastic methods into the vocabulary of the designer. Plastic theory offers a completely different way of approaching the structural problem, and it is this new approach which may prove to be of the most lasting importance. Measured against this background, Neal's book betrays that it was first written 10 years ago. The first four chapters, laying the foundations of the theory, are clearly and elegantly written; written to-day, however, the first chapter (on stress distributions) would largely disappear, and virtual work would be introduced earlier than Chapter 3. The four chapters forming the second half of the book deal with particular topics such as deflexions, minimum weight design, and shakedown, this last reflecting one of Prof. Neal's own research interests. The book as a whole gives the impression of being slightly old-fashioned; the first half is not quite incisive enough in its treatment of the basic theory, and the second is too detailed in its treatment of topics which are seen now to be not of prime importance. Overall, however, the book is probably still the best introduction a student could have to the plastic design of steel frames.

\section{The Habit of Authority}

Paternalism in British History. By A. P. Thornton. Pp. 402. (London: George Allen and Unwin, Ltd., 1966.) 45s, net.

IN spite of an early reference to William Whewell, Prof. Thornton's study of paternalism in British history comes no nearer than Prof. Hogben's Science in Authority to examining the rival claims of authority and of intellectual initiative. The book might be described as an exposition of Governor Morris's observation to Washington that the exercise of authority depends on personal character, but while Prof. Thornton seems to accept the view that expertise of any kind is ancillary to the tradition of authority and in itself gives none, he never urges the scientist to accept office and is little concerned with how the scientist or other expert can qualify himself to exercise leadership or authority. To that extent the book disappoints, and it lacks the interest for the scientist or technologist that its opening might suggest. Prof. Thornton describes with perspicuity and candour the tradition of successful paternalism which characterizes British history, and the pragmatism which pervades the book suggests that Prof. Thornton himself is well qualified to expand this into a badly needed analysis of the personal aspects of the place of the scientist in the task of government. That task is not attempted: there are occasional pointers or warnings but it is left to the scientist himself to make the analysis. Accordingly, while the book is entertaining as well as instructive, its scientific interest is slight. The title alone points to the existence of a problem central and inescapable for our times, whether we approach it primarily from the political side or from the kind of consideration which prompted Prof. R. S. Kuhn to discuss the structure of scientific revolutions. Nevertheless, in these seven chapters, discusaing in succession what Prof. Thornton terms the colonization of England, the Estates of the realm, English authority overseas, the dislocation of society, the survival of the ascendancy, Bonar Law's dynasty, and agents and patients, any one who attempts that task will find much that is instructive and suggestive. R. BRIGHTMaN 